\title{
Genotypic characterization of fluoroquinolone-resistant Escherichia coli isolates from edible offal
}

\author{
Se Hyun Son, Kwang Won Seo, Yeong Bin Kim, Eun Bi Noh, Keun-Woo Lee, Tae-Ho Oh, Seung-Joon Kim, \\ Jae-Chan Song, Tae-Wan Kim, Young Ju Lee* \\ College of Veterinary Medicine \& Zoonoses Research Institute, Kyungpook National University, Daegu 41566, Korea
}

\begin{abstract}
Edible offal is easily contaminated by Escherichia coli (E. coli) and fluoroquinolone (FQ)-resistant $E$. coli is considered a serious public health problem, thus, this study investigated the genetic characteristics of FQ-resistant $E$. coli from edible offal. A total of 22 FQ-resistant $E$. coli isolates were tested. A double mutation in each gyrA and parC led the highest MIC. Four (18.2\%) isolates carried plasmid-mediated quinolone resistance genes. The $\mathrm{fimH}$, eaeA, escV, ast $A$, and iucC genes were confirmed. Seventeen isolates $(77.3 \%)$ were positive for plasmid replicons. The isolates showed high genetic heterogeneity based on pulsed-field gel electrophoresis patterns.
\end{abstract}

Keywords: Escherichia coli; edible offal; fluoroquinolones; quinolone resistance-determining region; molecular typing

*Corresponding author

Young Ju Lee

College of Veterinary Medicine \& Zoonoses Research Institute, Kyungpook National University, 80 Daehak-ro, Daegu 41566, Korea

Tel: $+82-53-950-7793$

Fax: +82-505-950-7793

E-mail: youngju@knu.ac.kr

ORCID:

Se Hyun Son

https://orcid.org/0000-0003-0990-6637

Kwang Won Seo

https://orcid.org/0000-0003-1620-4916

Yeong Bin Kim

https://orcid.org/0000-0002-4754-0931

Eun Bi Noh

https://orcid.org/0000-0002-8039-3996

Young Ju Lee

https://orcid.org/0000-0001-6108-2845

Conflict of Interest

The authors declare no conflicts of interest.

Received: April 9, 2020

Revised: July 9, 2020

Accepted: July 10, 2020
Fluoroquinolones (FQs) are a group of antibiotics commonly prescribed for a variety of infections in both human and veterinary medicine. FQs are widely used worldwide because of their bactericidal effects against broad range of bacteria. However, due to the indiscriminate use of FQs, the rise of FQ-resistance in bacteria is regarded as a serious public health concern [1].

One of the main risk factors for infections caused by antimicrobial-resistant bacteria is contaminated food. Edible offal, which means non-muscular part of the food-producing animals' carcasses, is a common food product in many countries, but can be easily contaminated by $E$. coli present in the intestinal microflora during slaughter and processing [2]. Therefore, edible offal is a potential source of antimicrobial-resistant $E$. coli that can be transferred to humans via the food chain. Although several studies related to FQ-resistant $E$. coli in livestock and meat products have been conducted [3-5], their significance in edible offal has not been satisfactorily explored. The objective of the current study is to investigate genetic characteristics of FQ-resistant E. coli isolates from edible offal.

One hundred-eighteen $E$. coli isolates were collected from edible offal samples (the heart, liver, stomach or gizzard, small intestine, and large intestine) produced at 8 chicken, 9 pig, and 7 cattle slaughterhouses located in the central and southern regions of Korea from January to October 2017. The method for isolating $E$. coli was as follows: $25 \mathrm{~g}$ of each sample was incubated in $225 \mathrm{~mL}$ of modified EC broth with novobiocin (Merck, Germany) at $37^{\circ} \mathrm{C}$ for 18-24 h. After incubation, $0.1 \mathrm{~mL}$ of each broth was inoculated onto MacConkey agar (BD, USA) and incubated at $37^{\circ} \mathrm{C}$ for $18-24 \mathrm{~h}$. Among colonies on the agar, those identified as $m a l B$ gene-positive through polymerase chain reaction (PCR) analysis were confirmed as $E$. coli [6]. To find FQ-resistant $E$. coli, The $E$. coli colonies were streaked onto MacConkey agar containing 4 $\mathrm{mg} / \mathrm{L}$ ciprofloxacin (Sigma-Aldrich, USA) and incubated at $37^{\circ} \mathrm{C}$ for $18-24 \mathrm{~h}$. Twenty-two FQ-resistant $E$. coli isolates (12 isolates from chicken, 8 isolates from pig, and 2 isolates from cattle) were finally collected.

Disk diffusion test was performed to characterize the antimicrobial resistance profiles of FQ-resistant $E$. coli isolates according to the Clinical and Laboratory Standards Institute guidelines [7]. The antimicrobial disks (BD) used were nalidixic acid (NA, $30 \mu \mathrm{g}$ ), ciprofloxacin (CIP, $5 \mu \mathrm{g}$ ), ampicillin 
(AM, $10 \mu \mathrm{g})$, amoxicillin-clavulanate (AMC, 20/10 $\mu \mathrm{g})$, cefazolin (CZ, $30 \mu \mathrm{g})$, cefepime (FEP, $30 \mu \mathrm{g})$, cefotaxime (CTX, $30 \mu \mathrm{g}$ ), cefoxitin (FOX, $30 \mu \mathrm{g}$ ), cefuroxime (CXM, $30 \mu \mathrm{g}$ ), ceftazidime (CAZ, $30 \mu \mathrm{g})$, cephalexin (CL, $30 \mu \mathrm{g})$, cephalothin $(\mathrm{CF}, 30 \mu \mathrm{g})$, chloramphenicol $(\mathrm{C}, 30 \mu \mathrm{g})$, gentamicin (GM, $10 \mu \mathrm{g}$ ), imipenem (IPM, $10 \mu \mathrm{g}$ ), tetracycline (TE, $30 \mu \mathrm{g}$ ), and trimethoprim-sulfamethoxazole (SXT, 1.25/23.75 $\mu \mathrm{g}$ ). If several isolates from one sample had the same resistance patterns, only one isolate was randomly selected. Multidrug resistance (MDR) was defined as resistance to at least one agent in three or more antimicrobial classes [8]. Minimum inhibitory concentrations (MICs) of norfloxacin (NOR), CIP, and enrofloxacin (ENR) for FQ-resistant $E$. coli isolates were further determined using the agar dilution method. E. coli ATCC 25922 was used as a control strain.

The FQ-resistant $E$. coli isolates were subjected to the PCR method as described previously for detecting the plasmidmediated quinolone resistance (PMQR) genes (qnrA, qnrB, $q n r D$, qnrS, qepA, and aac(6')-Ib-cr) and the genes causing resistance to $\beta$-lactam antimicrobials $\left(b l a_{\mathrm{TEM}}, b l a_{\mathrm{SHV}}\right.$, and $\left.b l a_{\mathrm{OXA}}\right)$,

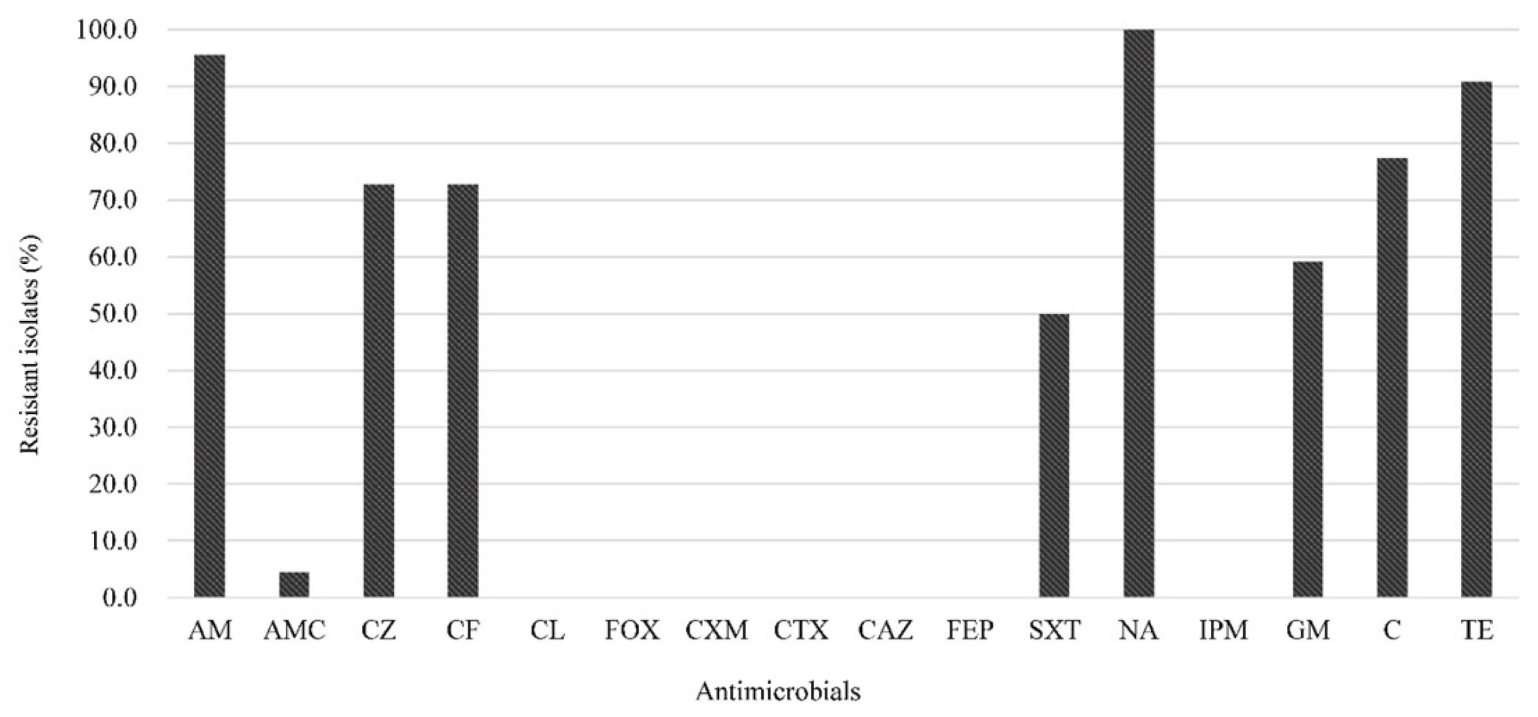

Fig. 1. Antimicrobial resistance patterns in 22 fluoroquinolone-resistant Escherichia coli isolates from edible offal. AM, ampicillin; AMC, amoxicillin-clavulanic acid; CZ, cefazolin; CF, cephalothin; CL, cephalexin; FOX, cefoxitin; CXM, cefuroxime; CTX, cefotaxime; CAZ, ceftazidime; FEP, cefepime; SXT, trimethoprim-sulfamethoxazole; NA, nalidixic acid; IPM, imipenem; GM, gentamicin; C, chloramphenicol; TE, tetracycline.

Table 1. Distribution of multidrug resistance pattern among 22 fluoroquinolone-resistant Escherichia coli isolates from edible offal

\begin{tabular}{|c|c|c|}
\hline $\begin{array}{l}\text { No. of antimicrobial classes shown } \\
\text { resistance }\end{array}$ & Resistance patterns & No. of isolates $(\%)$ \\
\hline 8 & PCNs-CEPs-FPIs-Qs-FQs-AMGs-PHs-TETs & $4(18.2)$ \\
\hline \multirow[t]{5}{*}{7} & PCNs-BL/BLICs-CEPs-Qs-FQs-AMGs-PHs & $1(4.5)$ \\
\hline & PCNs-CEPs-FPIs-Qs-FQs-AMGs-TETs & $1(4.5)$ \\
\hline & PCNs-CEPs-FPIs-Qs-FQs-PHs-TETs & $1(4.5)$ \\
\hline & PCNs-CEPs-Qs-FQs-AMGs-PHs-TETs & $6(27.3)$ \\
\hline & PCNs-FPIs-Qs-FQs-AMGs-PHs-TETs & $1(4.5)$ \\
\hline \multirow[t]{2}{*}{6} & PCNs-CEPs-FPIs-Qs-FQs-TETs & $4(18.2)$ \\
\hline & PCNs-CEPs-Qs-FQs-PHs-TETs & $1(4.5)$ \\
\hline \multirow[t]{2}{*}{5} & PCNs-CEPs-Qs-FQs-TETs & $1(4.5)$ \\
\hline & PCNs-Qs-FQs-PHs-TETs & $1(4.5)$ \\
\hline 4 & - & $0(0)$ \\
\hline \multirow[t]{2}{*}{3} & Qs-FQs-PHs & $1(4.5)$ \\
\hline & Total & $22(100)$ \\
\hline
\end{tabular}

PCNs, penicillins; BLICs, $\beta$-lactam/ $\beta$-lactamase inhibitor combinations; CEPs, cephems; FPIs, folate pathway inhibitors; Qs, quinolones; FQs, fluoroquinolones; AMGs, aminoglycosides; PHs, phenicols; TETs, tetracyclines. 
sulfonamide (sull and sul2), tetracycline (tetA and tetB), chloramphenicol (catAl and $\mathrm{cmlA}$ ), and aminoglycoside (aac(6')-Ib, aac(3)-II, and ant(2")-I) [6]. Mutations in the quinolone resistance-determining regions (QRDR) of the gyr $A$ and $\operatorname{parC}$ genes and other resistance genes were examined by DNA sequencing. The virulence factor genes associ- ated with pathotypes of E. coli (eaeA, escV, ent, bfpB, hly, stx1, stx2, ipaH, invE, aggR, pic, astA, elt, est, fimH, papC, $s f a / f o c D E$, and iucC) were also confirmed by PCR as previously described $[9,10]$. For detecting the 18 major plasmid replicons in Enterobacteriaceae, a PCR-based replicon typing was conducted as described previously [11].
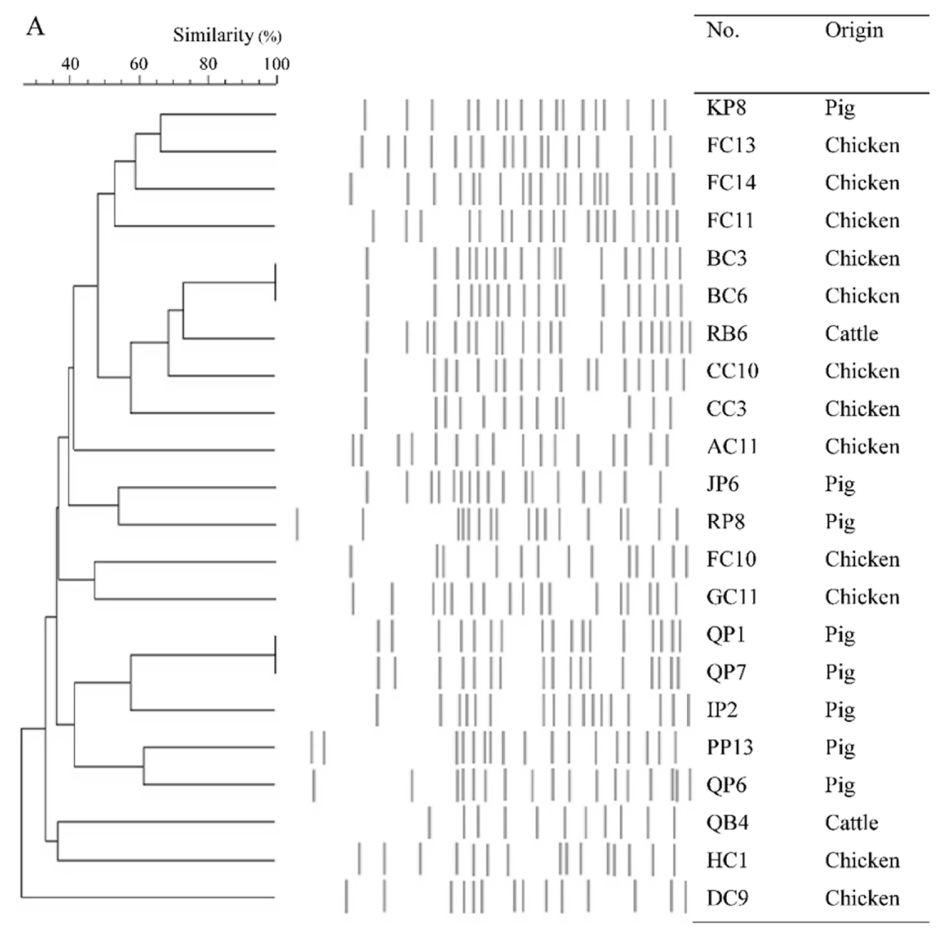

B

\begin{tabular}{|c|c|c|c|c|c|c|c|c|c|c|}
\hline \multirow[t]{2}{*}{ No. } & \multirow[t]{2}{*}{ Origin } & \multirow[t]{2}{*}{ PMQR } & \multicolumn{2}{|c|}{ QRDR mutations } & \multicolumn{3}{|c|}{ MIC $(\mu \mathrm{g} / \mathrm{ml})$} & \multirow[t]{2}{*}{ Other resistance genes } & \multirow[t]{2}{*}{ Virulence genes } & \multirow[t]{2}{*}{ Plasmid replicons } \\
\hline & & & gyrA & parC & NOR & CIP & ENR & & & \\
\hline KP8 & Pig & - & S83L, D87N & S80I & 64 & 32 & 32 & bla $a_{\text {TEM-1 }}, c m l A, \operatorname{tet} B$ & $\mathrm{fimH}$ & - \\
\hline $\mathrm{FC} 13$ & Chicken & - & S83L, D87N & S80I & 128 & 32 & 32 & $b l a_{\mathrm{TEM}-\mathrm{l}}, \operatorname{aac}(3)-I I, \operatorname{tet} A, \operatorname{tet} B$ & fimH, iисC & I1 \\
\hline $\mathrm{FC} 14$ & Chicken & - & D87N & S80I, E84G & $>512$ & 128 & $>512$ & 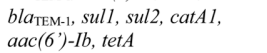 & fimH & FIB, Frep, Il \\
\hline $\mathrm{FC} 11$ & Chicken & - & S83L, D87N & S80I & 16 & 8 & 4 & bla $a_{\mathrm{TEM}-1}$, sul2, tetA & $\begin{array}{l}\text { eaeA, escV, } \\
\text { fimH, iucC }\end{array}$ & FIA, FIB, Frep, Y \\
\hline $\mathrm{BC} 3$ & Chicken & - & S83L & S80I, E84G & 256 & 64 & 128 & $b l a_{\mathrm{TEM}-\mathrm{l}}, c m l A, \operatorname{tet} B$ & $\mathrm{fimH}$ & FIB, FIC, Frep \\
\hline BC6 & Chicken & - & S83L & S80I, E84G & 256 & 64 & 128 & $b l a_{\mathrm{TEM}-\mathrm{I}}$, tet $B$ & fimH & FIB, Frep \\
\hline RB6 & Cattle & $q n r S$ & S83L, D87N & S80I, E84A & $>512$ & 64 & 128 & $\begin{array}{l}\text { bla }_{\text {TEM-1 }}, \text { sull, sul2, aac(3)-II, } \\
\operatorname{tet} B\end{array}$ & $\mathrm{fimH}$ & Frep \\
\hline $\mathrm{CC} 10$ & Chicken & - & S83L, D87N & S80I, E84G & $>512$ & 64 & $>512$ & $b l a_{\mathrm{IEM}-1}, c m l A, t e t B$ & $\mathrm{fimH}$ & FIB, I1, Frep \\
\hline $\mathrm{CC} 3$ & Chicken & - & S83L, D87N & S80I, E84G & 256 & 128 & $>512$ & $b l a_{\mathrm{TEM}-\mathrm{l}}, c m l A$, tet $B$ & $\mathrm{fimH}$ & FIB, I1, Frep \\
\hline $\mathrm{AC} 11$ & Chicken & - & S84L, D87N & S80I & 32 & 16 & 8 & bla $a_{\mathrm{TEM}-\mathrm{l}}$, tet $B$ & fimH, iucC & FIB, Frep \\
\hline JP6 & Pig & - & S83L, D87N & S80I, E84G & $>512$ & 128 & $>512$ & bla $a_{\mathrm{TEM}-\mathrm{l}}$, sull,, $\mathrm{cml} A$, tet $B$ & $\mathrm{fimH}$ & FIB, Frep \\
\hline RP8 & Pig & - & S83L, D87N & $\mathrm{S} 80 \mathrm{I}$ & 128 & 32 & 128 & - & $\mathrm{fimH}$ & - \\
\hline $\mathrm{FC} 10$ & Chicken & - & D87N & S80I & 16 & 8 & 4 & $\begin{array}{l}\text { bla } \\
\text { tetAM-1, sul } 2, \text { cmlA, aac(3)-II, }\end{array}$ & $\mathrm{fimH}$ & FIB, Frep \\
\hline GC11 & Chicken & - & $\begin{array}{l}\text { S83L, } \\
\text { D87Y }\end{array}$ & S80I & 16 & 8 & 32 & bla $a_{\mathrm{TEM}-1}$, tetA & astA, fimH & - \\
\hline QP1 & Pig & $q n r A$ & S83L, D87N & S80I & 16 & 8 & 8 & bla $a_{\text {TEM-l, }}$, sull, sul $2, \mathrm{cmlA}, \operatorname{tet} B$ & $\mathrm{fimH}$ & Frep \\
\hline QP7 & Pig & $q n r A$ & S83L, D87N & S80I & 64 & 8 & 8 & bla $_{\mathrm{TEM}-1}$, sull, sul2, tet $B$ & $\mathrm{fimH}$ & Frep \\
\hline IP2 & Pig & - & $\mathrm{S} 83 \mathrm{~L}$ & S80I & 16 & 16 & 8 & $\begin{array}{l}\text { bla } a_{\mathrm{TEM}-1}, \text { sull, sul2, cmlA, tetA, } \\
\operatorname{tet} B\end{array}$ & fimH & FIB, FIC, I1, Frep \\
\hline PP13 & Pig & - & $\begin{array}{l}\text { S83L, } \\
\text { D87N }\end{array}$ & S80I & 64 & 16 & 8 & bla $a_{\mathrm{TEM}-1}$, tet $A$ & $\mathrm{fimH}$ & - \\
\hline QP6 & Pig & - & S83L, D87N & S80I & 16 & 8 & 8 & $b l a_{\mathrm{TEM}-1}, \operatorname{aac}(3)-I I$, tetA & $\mathrm{fimH}$ & - \\
\hline QB4 & Cattle & $\begin{array}{l}q n r S, \\
a a c\left(6^{\prime}\right)-I b-c r\end{array}$ & S83L & - & 8 & 8 & 8 & bla $a_{\mathrm{TEM}-1}, b l a_{O X A-2}$, & fimH, iucC & FIA,FIB, I1, HI1, N, HI2, Frep \\
\hline $\mathrm{HC} 1$ & Chicken & - & D87N & S80I & 64 & 16 & 32 & bla & astA, fimH & FIB, Frep \\
\hline DC9 & Chicken & - & S83L, D87N & $\mathrm{S} 80 \mathrm{R}$ & 8 & 16 & 8 & bla ${ }_{\mathrm{TEM}-\mathrm{l}}$, sull, sul2, tetA & astA, fimH & Y,Il, Frep \\
\hline
\end{tabular}

Fig. 2. Genetic characteristics of 22 fluoroquinolone-resistant Escherichia coli isolates from edible offal. (A) Pulsed-field gel electrophoresis patterns for the E. coli isolates. (B) Antimicrobial resistance, virulence genes, and plasmid profiles of the $E$. coli isolates. NOR, norfloxacin; CIP, ciprofloxacin; ENR, enrofloxacin. 
Pulsed-field gel electrophoresis (PFGE) of the FQ-resistant $E$. coli isolates was performed in accordance with CDC PulseNet protocol [12], using a CHEF-Mapper apparatus (Bio-Rad Laboratories, USA). The dendrogram of PFGE patterns was constructed via Dice coefficients and the unweighted pair group method with arithmetic mean (UPGMA).

The antimicrobial resistance patterns of 22 FQ-resistant $E$. coli isolates are shown in Fig. 1. FQ-resistant E. coli isolates showed the highest resistance to AM $(95.5 \%)$ and TE $(90.9 \%)$, similar to previous studies on the high prevalence of $\mathrm{AM}$ and $\mathrm{TE}$ resistance from FQ-resistant E. coli from chicken [5] and pigs [3] in Korea. All of the FQ-resistant isolates were also classified as MDR (Table 1), consistent with the report by $\mathrm{Hu}$ et al. [3] that $91.5 \%$ of the FQ-resistant $E$. coli isolates showed MDR. Although it is unknown whether there is a direct relationship between FQ-resistance and MDR, this result is not surprising because sales of livestock antimicrobials in Korea have been steadily increasing since 2013, with penicillins and tetracyclines sold more than other antibiotics [13].

Comparison of MIC values and genetic characteristics related to the FQ-resistance of the isolates are presented in Fig. 2. The QRDR mutations in FQ target genes, such as gyrA and parC, play a significant role in the mechanism of FQ resistance in bacteria [1]. Similar to previous study in Korea [3], S83L (18 isolates, 81.8\%) and D87N (17 isolates, $77.3 \%$ ) substations in gyrA and the S80I substation (20 isolates, $90.9 \%$ ) in parC were found to be widespread. Four isolates carried a double mutation in each gyrA and $\operatorname{par} C$, and three isolates carried a single mutation in gyr $A$ and a double mutation in parC showed the highest MIC ranges $(\geq 256 \mu \mathrm{g} /$ $\mathrm{mL}$ for NOR, 64 to $128 \mu \mathrm{g} / \mathrm{mL}$ for CIP, and $\geq 128 \mu \mathrm{g} / \mathrm{mL}$ for ENR). Four isolates which carried a single mutation in both gyrA and parC or gyrA only showed MICs $\leq 32 \mu \mathrm{g} / \mathrm{mL}$ for FQs. In consistent with these results, Moon et al. [14] also reported that double mutations in parC led to significantly increased MIC values for FQs. The PMQR genes were detected in $18.2 \%$ of FQ-resistant isolates, which is similar to that $(15.3 \%)$ of pig fecal-derived isolates [3] and higher than that $(5.56 \%)$ of chicken isolates [4] in Korea. Although PMQR genes do not produce high quinolone resistance by themselves, they can facilitate the selection of higher levels of quinolone resistance [5]. The additional antimicrobial resistance genes $b l a_{\mathrm{TEM}-1}, b_{\text {OXA-2 }}$, sull, sul2, catAl, cmlA, aac(6')$I b$, aac(3)-II, tetA, and tetB were also detected, which suggests that FQ-resistant $E$. coli may carry resistances against many different antimicrobials as well as deliver FQ-resistance to other bacteria.

A total of five virulence-associated genes (eaeA, escV, ast A, fim $H$, and $i u c C$ ) were found in the isolates tested (Fig. 2). All 22 FQ-resistant isolates were found to have the $f i m H$ gene in their distribution of virulence genes. The iuc gene was detected in four isolates, the ast $A$ gene in three isolates, and the eae $A$ and esc $V$ genes in one identical isolate. It has been reported that $\mathrm{fimH}$, the type 1 fimbrial adhesin gene, and $i u c C$, the aerobactin synthase gene, are common in uropathogenic $E$. coli [10]. In addition, the eae $A$, esc $V$, and ast $A$ genes contribute to the pathogenicity of diarrheagenic E. coli [9].

Also, 17 FQ-resistant isolates were positive for any one of the 18 plasmid replicons (Fig. 2). Plasmids are small DNA molecules that are distinct from chromosomes and can provide beneficial effects to bacteria such as antibiotic resistance through horizontal gene transfer [11]. Frep (16 isolates, 94.1\%) and FIB (12 isolates, 70.6\%), which belong to the IncF group thought to play an important role in the spread of virulence and MDR among Enterobacteriaceae [15], were more frequent than other replicon types.

$X b a$ I PFGE analysis identified a total of 20 clusters with $\geq 85 \%$ similarity (Fig. 2). The PFGE patterns of the FQresistant isolates revealed generally high genomic diversity $(<50 \%)$. However, two isolates obtained from chicken (BC3 and $\mathrm{BC} 6)$ and pig (QP1 and QP7), respectively, showed the same PFGE patterns. The isolates with identical PFGE patterns were harvested from samples from the same slaughterhouses, suggesting the possibility of cross-contamination of clonal strains during slaughter and processing.

In conclusion, this study provides evidence for the role of edible offal in the dissemination of FQ-resistance in humans via the food chain and shows importance of enhancing hygiene to reduce the cross-contamination in the production of edible offal.

\section{Acknowledgements}

This work was supported by Korea Institute of Planning and Evaluation for Technology in Food, Agriculture and Forestry (IPET) through Agriculture, Food and Rural Affairs Convergence Technologies Program for Educating Creative Global Leader, funded by Ministry of Agriculture, Food and Rural Affairs (MAFRA; 716002-7).

\section{References}

1. Redgrave LS, Sutton SB, Webber MA, Piddock LJ. Fluoroquinolone resistance: mechanisms, impact on bacteria, and role in evolutionary success. Trends Microbiol 2014;22: 438-445.

2. Saide-Albornoz JJ, Knipe CL, Murano EA, Beran GW. Contamination of pork carcasses during slaughter, fabrication, and chilled storage. J Food Prot 1995;58:993-997.

3. Hu YS, Shin S, Park YH, Park KT. Prevalence and mechanism of fluoroquinolone resistance in Escherichia coli isolated from swine feces in Korea. J Food Prot 2017;80: 1145-1151.

4. Koo HJ, Woo GJ. Characterization of antimicrobial resistance of Escherichia coli recovered from foods of animal and fish origin in Korea. J Food Prot 2012;75:966-972.

5. Oh JY, Kwon YK, Tamang MD, Jang HK, Jeong OM, Lee HS, Kang MS. Plasmid-mediated quinolone resistance in Escherichia coli isolates from wild birds and chickens in South Korea. Microb Drug Resist 2016;22:69-79.

6. Son SH, Seo KW, Kim YB, Jeon HY, Noh EB, Lee YJ. 
Molecular characterization of multidrug-resistant Escherichia coli isolates from edible offal in Korea. J Food Prot 2019; 82:1183-1190.

7. Clinical and Laboratory Standards Institute (CLSI). Performance Standards for Antimicrobial Susceptibility Testing; Twentythird Informational Supplement. CLSI document M100-S23. Wayne: Clinical and Laboratory Standards Institute; 2013.

8. Magiorakos AP, Srinivasan A, Carey RB, Carmeli Y, Falagas ME, Giske CG, Harbarth S, Hindler JF, Kahlmeter G, OlssonLiljequist B, Paterson DL, Rice LB, Stelling J, Struelens MJ, Vatopoulos A, Weber JT, Monnet DL. Multidrug-resistant, extensively drug-resistant and pandrug-resistant bacteria: an international expert proposal for interim standard definitions for acquired resistance. Clin Microbiol Infect 2012;18:268281.

9. Kagambèga A, Martikainen $\mathrm{O}$, Lienemann $\mathrm{T}$, Siitonen A, Traor AS, Barro N, Haukka K. Diarrheagenic Escherichia coli detected by 16-plex PCR in raw meat and beef intestines sold at local markets in Ouagadougou, Burkina Faso. Int J Food Microbiol 2012;153:154-158.

10. Tarchouna M, Ferjani A, Ben-Selma W, Boukadida J. Distribution of uropathogenic virulence genes in Escherichia coli isolated from patients with urinary tract infection. Int $\mathrm{J}$
Infect Dis 2013;17:e450-e453.

11. Johnson TJ, Wannemuehler YM, Johnson SJ, Logue CM, White DG, Doetkott C, Nolan LK. Plasmid replicon typing of commensal and pathogenic Escherichia coli isolates. Appl Environ Microbiol 2007;73:1976-1983.

12. Ribot EM, Fair MA, Gautom R, Cameron DN, Hunter SB, Swaminathan B, Barrett TJ. Standardization of pulsed-field gel electrophoresis protocols for the subtyping of Escherichia coli O157:H7, Salmonella, and Shigella for PulseNet. Foodborne Pathog Dis 2006;3:59-67.

13. Animal and Plant Quarantine Agency (APQA). National Antimicrobial Resistance Monitoring Program. Available from: https://ebook.qia.go.kr/20180704_110723.

14. Moon DC, Seol SY, Gurung $\bar{M}$, Jin JS, Choi $\mathrm{CH}$, Kim J, Lee YC, Cho DT, Lee JC. Emergence of a new mutation and its accumulation in the topoisomerase IV gene confers high levels of resistance to fluoroquinolones in Escherichia coli isolates. Int J Antimicrob Agents 2010;35:76-79.

15. Yang QE, Sun J, Li L, Deng H, Liu BT, Fang LX, Liao XP, Liu YH. IncF plasmid diversity in multi-drug resistant Escherichia coli strains from animals in China. Front Microbiol 2015;6:964. 